\title{
Exploration of the Spatial Division of Labor to Regional Economic Growth in Yangtze River Delta
}

\author{
Zhuolin Xiao \\ Department of Food and Pharmacy, Qingyuan Polytechnic, Qingyuan City, Guangdong Province, China \\ Email: 675023800@qq.com
}

\begin{abstract}
In order to construct a complete and unified theoretical basis of spatial division of labor and regional economic growth, an analytical framework of spatial division of labor, which is "microfoundation-mechanism-industry, city and enterprise three carriers", is constructed and an empirical study of it is made. The results show that, in the future, it is necessary to improve the level of spatial division of labor in manufacturing industry and give full play to the agglomeration economic advantages of spatial division of labor in manufacturing industry; spatial division of labor has a significant positive correlation with regional economic growth; the degree of specialization of service industry has been continuously improved, and now it has developed to a higher level; in the aspect of urban carriers, different stage, speed and competitiveness of urban development and the problems faced will be different. In terms of enterprise carriers, the Yangtze River Delta region actively introduces and goes out. Through the joint action of domestic and foreign enterprises, it effectively promotes the level in the international division of labor system, and the enterprise economic structure is improved day by day.
\end{abstract}

Keywords: Specialized division, spatial division, economic linkages, economic growth, the Yangtze River Delta.

\section{Introduction}

Based on the evolution of national policies and the tightness of spatial economic ties, it is of great significance to build the Yangtze River Delta into a competitive economic network system, improve the level of spatial division of labor, maintain the agglomeration economy of expanding spatial division of labor, and participate in the global production chain [1]. At present, the research on spatial division of labor in the Yangtze River Delta region is mainly concentrated in provincial-level regions. Even if the prefecture-level and high level city data are used, it is only a few cities within a province or within the Yangtze River Delta region. Although the literature on economic growth in the Yangtze River Delta region has been very rich, the existing research is seldom combined with the analysis of spatial division of labor. How is the role of spatial division of labor on the promotion of productivity and economic growth in the Yangtze River Delta region? This is a question worthy of deep thinking. Therefore, the relationship between spatial division and economic growth in the Yangtze River Delta region is selected to study [2].

\section{Literature Review}

Relevant research abroad is mainly conducted from the various factors in specialized division of labor, spatial division of labor and economic growth, industrial development, and urban development. In 1979, Massey pointed out that investment in new economic activities was geographically distributed over any given period of time, leading to a spatial division of labor. Since the 1990s, there have been more and more literatures on the study of regional development and urban spatial structure by spatial division of labor. Since the beginning of the 21st century, the study of specialization, spatial division, externality and industrial agglomeration has been continuing. The spatial division and agglomeration of service industry have a significant impact on urban spatial reconstruction and function upgrading [3,4].

Domestic research started from 1990s and produced more results after twenty-first Century. The general survey mainly includes the following aspects. From the perspective of the division of labor space, 
the study includes cities, urban industries, urban agglomerations and city distinguish. Secondly, it is the research on the evolution and mechanism of spatial division in metropolitan area. Third, the researches pay attention to the spatial division of labor of industry and study the spatial division of labor in manufacturing industry. The fourth is regional division of labor and regional spatial division of labor. The fifth is exploring the relationship between division of labor and industrial agglomeration and cluster.

However, most studies confuse the connotation of division of labor and spatial division of labor, and do not form a complete theory of spatial division of labor; lack of interpretation of the micro-basis of spatial division of labor. Based on Massey's definition of spatial division of labor, combined with transaction cost theory and new classical economic division of labor theory, a theoretical analysis framework is constructed from the micro-basis of spatial division of labor, the mechanism of promoting regional economic growth and the carrier, the understanding of spatial division of labor and regional economic growth is deepened, and relevant research is enriched [6].

\section{Characteristics of Effective Carrier Spatial Division of Labor in Yangtze River Delta Region}

\subsection{Characteristics and Influencing Factors of Spatial Division of Labor in Manufacturing Industry}

The level of specialization of manufacturing industry in the Yangtze River Delta region is increasing. At present, the division of labor is more dependent on capital and technology. However, there are differences in the intensity of specialization among different manufacturing industries in each city, and the number and names of industries with specialization advantages in different cities are different. Although different cities have the same or one dominant industry, the specific values are different. Based on the panel data, the factors that affect the spatial division of labor in manufacturing industry are analyzed, and the bi-directional fixed effect model is chosen to determine the estimated coefficients of each explanatory variable after many tests. It is found that historical factors and the relative scale of industries have a positive impact on the level of spatial division of labor in manufacturing industry, while the scale economy of industries and owner's rights and interests have a negative impact.

\subsection{Characteristics and Effects of Spatial Division of Service Industry and Its Influencing Factors}

In the ten years between 2004-2014, the level of service industry specialization in the Yangtze River Delta cities has risen and fallen, and it is overall improved. The trend of outward diffusion of service industry concentration areas has further strengthened. On the whole, a Z-shaped service corridor belt is formed, which is "Nanjing-Zhenjiang-Changzhou-Wuxi-Suzhou-Shanghai-Jiaxing-Hangzhou-ShaoxingNingbo-Zhoushan".

By means of spatial econometric analysis, the influencing factors of spatial division of labor in service industry are examined. It is found that the urbanization level and the information flow coefficient between cities are positive and significant. The export level, the internal scale economy and the transportation level coefficient are negative and significant, while the other variables are mostly positive but not significant. Therefore, enhancing the level of urbanization, strengthening the construction of information and communication facilities and promoting information exchange will help to improve the level of spatial division of labor in the service industry.

\subsection{Characteristics of Urban Spatial Division of Labor}

The industrial specialization level in the Yangtze River Delta region is relatively low, and the distribution of industries in the space is more dispersed. There is a negative correlation between the specialization level of urban industry and the competitiveness of urban circles. In the 2004-2014 years, the level of industrial specialization continued to increase. The level of urban functional specialization is positively correlated with the competitiveness of urban agglomeration, but the overall value of functional specialization index is gradually decreasing. Shanghai has the highest level of functional 
specialization and the rising trend is obvious. There is an obvious spatial division of labor of "management department - production department" between the central cities, the sub-central city circle, the sub-sub-central city and the radiation city circle.

\subsection{Development and Change of Enterprise Economic Structure and the Spatial Layout and Network Structure of Enterprises}

The number and amount of contracts and actual foreign direct investment projects in the Yangtze River Delta region continue to increase, and the level of utilization of foreign capital rises, which can be divided into three stages: reform and opening up to 1990, 1990-2000 and 2000-present. The Yangtze River Delta region has the characteristics of industrial advantages, technological advantages and strong consumer demand, and is in the forefront of emerging industries, technological industries and logistics industries. Affected by location, industrial links, economic development level, transportation conditions and other factors, most of the subsidiaries of Fortune China 500 enterprises in the region are located in the Yangtze River Delta region. According to the specific production layout of enterprises, it can be divided into three types: intra-provincial distribution, Yangtze River Delta regional distribution, other regions in China outside the Yangtze River Delta, and national and global distribution. It has formed a closely interwoven network of enterprise links and has a certain depth of spatial division of labor. Among them, the enterprise economy of central city and the sub-central city circle layer has closer relations.

\section{Economic Growth under the Effective Carrier Spatial Division of Labor in the Yangtze River Delta Region}

\subsection{Economic Growth under the Spatial Division of Labor in Manufacturing Industry}

Based on the mechanism of spatial division of labor promoting regional economic growth and the theoretical model of spatial division of labor, a hypothesis is established: the economic growth effect of spatial division of labor in manufacturing industry is obvious. The measurement model of spatial division of labor in manufacturing industry is constructed as follows:

$$
\ln G l O V_{i j t}=S_{i j t}+\ln K_{i j t}+\ln L_{i j t}+\alpha G_{i j t}+\varepsilon_{i j t}
$$

In the model, $\mathrm{i}$ indicates $\mathrm{i}$ area, $\mathrm{j}$ suggests $\mathrm{j}$ industry, $\mathrm{t}$ refers to time, $\mathrm{S}_{\mathrm{ijt}}$ is constant, and $\mathrm{G}_{\mathrm{ijt}}, \mathrm{GLOV}_{\mathrm{ijt}}$, $\mathrm{K}_{\mathrm{ijt}}$ and $\mathrm{L}_{\mathrm{ijt}}$ in turn shows the level of spatial division of labor, total industrial output value, total assets and employees in the period of $\mathrm{t}$ for $\mathrm{j}$ industry in area i. Tested by LM, chilar2(01)=1293.42 and Prob $>$ chibar $2=0.0000$. The RE model is better than the hybrid regression, and the RE model is the most suitable after combining all kinds of test results.

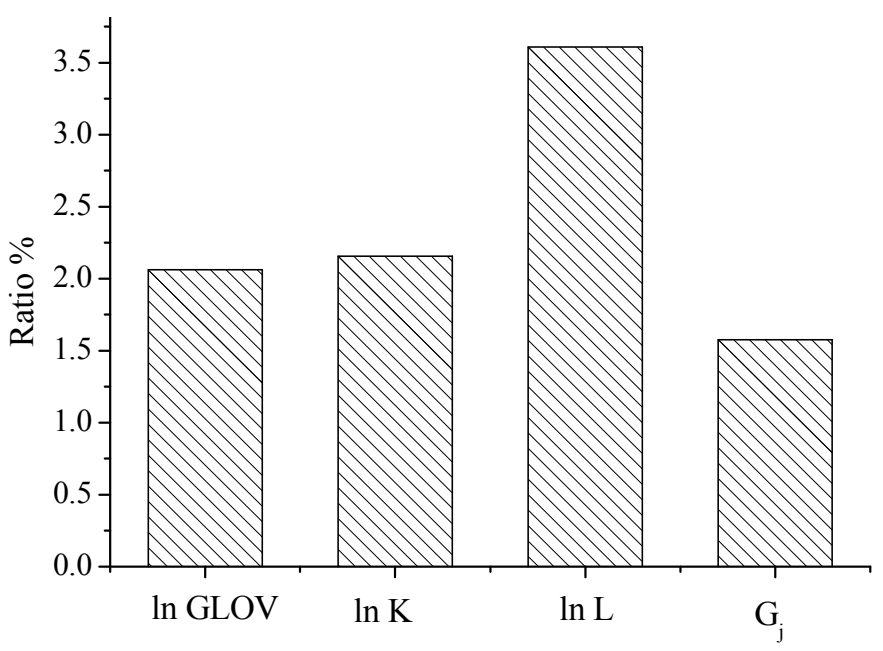

Figure 1. Description of spatial division of labor measurement model variables in manufacturing industry 
It can be concluded that the spatial division of labor in manufacturing industry in the Yangtze River Delta region has a positive impact on economic growth with a coefficient of 0.20847 , which verifies the hypothesis. From the perspective of industrial spatial division of labor, it mainly lies in the fact that industries are more centralized in one or some cities to facilitate forward-backward linkages and labor sharing. From the perspective of functional spatial division of labor, management department and research and development department need to concentrate on the regional core cities and central location of cities, and further strengthen the agglomeration economy of the spatial division of labor in manufacturing space in the economic circle.

\subsection{Economic Growth under the Spatial Division of Service Industry}

The single sample K-S test showed that the distribution was normal with the ln TlOV data, and the Pearson correlation coefficient bilateral test $(\mathrm{T})$ was used to calculate the correlation coefficient between the two variables, which was 10.7471. The correlation was strong and significant at the level of 0.01 . By model estimation, it is found that the logarithmic function containing constant in the equation is suitable. The logarithmic model formed with $\ln \mathrm{TlOV}$ is:

$$
\ln T l O V=3.656+0.324 \ln D_{i}
$$

$\mathrm{R}^{2}$ is $0.691, \mathrm{~F}$ is 51.362 , $\mathrm{Sig}$ is 0.000 , and $\mathrm{D}_{\mathrm{i}}>0.0057$. It can be sure that $\ln \mathrm{TlOV}>1.9715$ and the grater $D_{i}$ is, the greater ln TlOV will be. In the range of $0<D_{i}<2.40 \%$ and $0<\ln 10 V<13.4642$, when $D_{i}$ exceeds 2.4092, ln $10 \mathrm{~V}$ increases with the increase of $\mathrm{D}_{\mathrm{i}}$. This model can explain the role of spatial division of service industry in promoting economic growth, and verify the correctness of the above empirical content.

\subsection{Urban Spatial Economic Linkage}

The calculation results show that the explanatory power of urban GDP, the value added of secondary industry and the value added of tertiary industry is close to each other, but the regression coefficients are quite different. The regression coefficients are $0.263,0.678$ and 0.408 , respectively. It suggests that $F_{i}$ increases 263 units for every increase unit of urban GDP without considering other factors. $\mathrm{F}_{\mathrm{i}}$ adds 678 units for each unit of added value of urban secondary industry, and 408 units for each unit of added value of urban tertiary industry. The order of influence degree is secondary industry added value $>$ tertiary industry added value $>$ GDP, which shows that industry occupies the first place in the outward service capacity of urban development, and the traditional physical communication between cities is still very important. At the same time, capital, technology, information and other exchanges related to the tertiary industry are gradually increasing. Productive and consumer services are playing an increasingly important role.

Table 1. Correlation test of urban flow intensity statistical model variables

\begin{tabular}{cccccc}
\hline & & $\mathrm{F}_{\mathrm{i}}$ & GDP & ECZJ & SCZJ \\
\hline \multirow{3}{*}{$\mathrm{F}_{\mathrm{i}}$} & Pearson correlation & 1 & 0.926 & 0.923 & 0.904 \\
& Significance (both sides) & & 0.000 & 0.000 & 0.000 \\
& $\mathrm{~N}$ & 25 & 25 & 25 & 25 \\
\hline \multirow{3}{*}{ GDP } & Pearson correlation & 0.926 & 1 & 0.974 & 0.989 \\
& Significance (both sides) & 0.000 & & 0.000 & 0.000 \\
& $\mathrm{~N}$ & 25 & 25 & 25 & 25 \\
\hline \multirow{3}{*}{ ECZJ } & Pearson correlation & 0.923 & 0.974 & 1 & 0.930 \\
& Significance (both sides) & 0.000 & 0.000 & & 0.000 \\
& N & 25 & 25 & 25 & 25 \\
\hline \multirow{3}{*}{ SCZJ } & Pearson correlation & 0.904 & 0.989 & 0.930 & \\
& Significance (both sides) & 0.000 & 0.000 & 0.000 & 25 \\
\hline
\end{tabular}




\subsection{Economic Growth under the Spatial Division of Labor of Enterprises}

The hypothesis is constructed based on the mechanism of spatial division of labor to promote regional economic growth and the theoretical model of spatial division of labor: The economic increase effect of spatial division pf labor is obvious. The measurement model of spatial division of labor is constructed as follows:

$$
\ln (\mathrm{Y} / \mathrm{L})_{\mathrm{it}}=S_{i t}+\ln (\mathrm{Y} / \mathrm{L})_{\mathrm{it}}+\alpha H_{c i t}+\varepsilon_{i t}
$$

The two-way fixed effect model is the most suitable after synthesizing all kinds of test results, which can prove the correctness of the hypothesis. The economic growth effect of enterprise spatial division of labor is statistically significant. In the period studied, when the degree of enterprise spatial division of labor is increased by one unit, the economic level of Yangtze River Delta region will increase by $149.306 \%$. The effect of enterprise spatial division of labor on economic growth is obvious, but it is found that, according to the actual measurement in 2004-2014, the value of spatial division of labor in cities in the Yangtze River Delta region fluctuates little and changes slowly.

\section{Conclusion}

A theoretical model of spatial division of labor is built on the basis of specialized division of labor model, and it is proved that spatial division of labor under different patterns of specialized division of labor can promote regional economic growth. The empirical results of manufacturing, service industry, city, enterprise spatial division of labor and economic growth in the Yangtze River Delta show that the level of spatial division of labor in manufacturing industry is high, which is positively correlated with regional economic growth. The spillover effect of spatial division of labor in service industry is obvious, which has a positive effect on regional economic growth. The contribution of spatial division of labor in service industry to economic growth is positive as a whole, but it will also have a certain negative impact. The frequent division transaction of labor between cities, the increasingly close economic ties, the overall coordination of spatial division of labor in the whole region, and the promotion of the healthy development of special economy helps to promote the city's outward-looking functional links. The location layout of enterprises is diversified and the network structure tends to be complex.

\section{References}

1. Stringhini, S., et al. Socio-economic trajectories and cardiovascular disease mortality in older people: the English Longitudinal Study of Ageing. International Journal of Epidemiology 47.1(2017).

2. Huang-Lachmann, Jo Ting, M. Hannemann, and E. Guenther. Identifying Links between Economic Opportunities and Climate Change Adaptation: Empirical Evidence of 63 Cities. Ecological Economics 145(2018):231-243.

3. Gagolewski, Marek, M. Bartoszuk, and A. Cena. Genie: A new, fast, and outlier-resistant hierarchical clustering algorithm. Information Sciences 363(2017):8-23.

4. Bohn, M. O., et al. Quantitative Trait Loci Mapping of Western Corn Rootworm (Coleoptera: Chrysomelidae) Host Plant Resistance in Two Populations of Doubled Haploid Lines in Maize (Zea mays L.). Journal of Economic Entomology 44.5(2018):1749.

5. Song, Xie Yan, et al. The Giant Xiarihamu Ni-Co Sulfide Deposit in the East Kunlun Orogenic Belt, Northern Tibet Plateau, China. Economic Geology 111.1(2016):29-55.

6. Simony, S. B., et al. Effect of socioeconomic position on survival after childhood cancer in Denmark. Acta Oncologica 55.6(2016):1-9. 